\title{
Proposta de modelo NEAT para jogar One Night Ultimate Werewolf
}

\author{
Rafael Ferreira Costa ${ }^{\dagger}$ \\ Ciência da Computação \\ Univali \\ Itajaí, Brasil \\ rafaelferreiracosta26@gmail.com
}

\author{
Alisson Steffens Henrique \\ Mestrado em Computação Aplicada \\ Univali \\ Itajaí, Brasil \\ ali.steffens@gmail.com
}

\author{
Rodrigo Lyra \\ Laboratório de Inteligência Aplicada \\ Univali \\ Itajaí, Brasil \\ rlyra@univali.br
}

\author{
Anita Maria da Rocha Fernandes \\ Laboratório de Inteligência Aplicada \\ Univali \\ Florianópolis, Brasil \\ anita.fernandes@univali.br
}

\author{
Rudimar Luis Scaranto Dazzi \\ Laboratório de Inteligência Aplicada \\ Univali \\ Itajaí, Brasil \\ rudimar@univali.br
}

\begin{abstract}
The use of Artificial Intelligence approaches as NPCs in games is a very common practice, as they seek to convey the impression to players that these characters are somewhat autonomous. One of the approaches used is the technique called NEAT, which consists of making use of artificial neural networks together with genetic algorithms to manage the topology, connections, and weights of a network in an adaptive way. This work presents the proposal to create an NPC for games in a subcategory of board games, those based on bluff and incomplete information. The game used as a case study is One Night Ultimate Werewolf, a social deduction game, so that information is incomplete for players, and part of them must use the bluff in order to confuse other players. The objective is to evaluate the possibility of modeling the behaviors of this type of game for the application of NEAT.
\end{abstract}

\section{KEYWORDS}

NEAT, NPC, Jogo de Tabuleiro, Inteligência Artificial, One Night Ultimate Werewolf

\section{INTRODUÇÃO}

Jogos são divertidos quando conseguem manter o engajamento dos seus jogadores [1]. Para alcançar este estado de imersão, é preciso que o jogo entregue uma experiência que possua dificuldade equilibrada, trazendo desafios de uma forma que não seja frustrante ao jogador [2].

Comumente, jogos são usados como ferramenta para desenvolver novas técnicas de Inteligência Artificial, por meio dos NPCs (Non-Player Characters), já que os jogos tendem a apresentar semelhanças com problemas do mundo real em várias áreas. Sendo assim, são ótimos ambientes para aplicar e testar técnicas de Inteligência Artificial [3].

A maioria das inteligências em jogos é determinística e não se adapta ao jogador [4]. Com o intuito de proporcionar uma experiência equilibrada e empolgante, os NPCs devem se adaptar ao nível de habilidade do jogador ou até mesmo parecer com outro jogador. Uma das forma de alcançar isso foi utilizada em Journey, reduzindo a comunicação entre os jogadores para apenas sinais sonoros, um curto e um longo [5, 6].

A literatura aponta o uso de diversas técnicas para tais finalidades, entre elas, o uso de redes neurais e algoritmos genéticos [7]. Apesar de serem capazes de realizar seus objetivos, não são incomuns exemplos em que o uso dessas técnicas isoladas não é o suficiente em jogos [8,9].

Usando como estudo de caso o jogo One Night Ultimate Werewolf [10] por ser um jogo de dedução social, no qual os jogadores são divididos em dois grupos, os aldeões, que não sabem o papel uns dos outros, e os lobisomens que conhecem suas identidades. O objetivo do jogo é que os aldeões identifiquem ao menos um lobisomem enquanto os lobisomens tentam não serem descobertos. Isso acontece por meio de conversas entre os jogadores, trocando informações reais com informações falsas trazidas pelos lobisomens, e uma votação simultânea ao fim.

Este trabalho propõe uma modelagem de sistema que permita aplicar a técnica NEAT (NeuroEvolution Through Augmenting Topologies), que usa redes neurais juntamente com algoritmos genéticos para evoluir a topologia, parâmetros e as conexões da rede [11], para definir o voto do jogador.

O processo de evolução do NEAT se mostra poderoso e eficiente ao evoluir suas redes neurais comparado com outras técnicas de finalidade similar. Por meio da evolução tanto da topologia quanto dos pesos da rede, além de manter traços histórico de seus genes a fim de gerar bons indivíduos e assim almejando reduzir o espaço de busca por uma rede eficaz [11].

\section{SOLUÇÃO PROPOSTA}

A proposta desse trabalho consiste em modelar uma versão do jogo One Night Ultimate Werewolf, onde as fases de conversas e blefe possam ser discretizadas para servirem de entrada ao NEAT. Para isso pretende-se criar uma versão simplificada do jogo com a ferramenta Unity3D. 
O jogo consiste em três etapas, e em cada uma delas sendo usadas técnicas diferentes (demonstradas na Figura 1). A primeira é a etapa da noite, nesse momento os jogadores as realizam ações especiais referentes as suas cartas. Por não haver estratégias otimizadas, as ações que o NPC realiza nessa etapa serão sorteadas e armazenadas. Durante a etapa do dia, é o momento que os jogadores trocam as informações que possuem. Esta etapa está dividia em quatro turnos, e a forma que o NPC irá interagir com os outros jogadores e compartilhar suas informações está definida por meio de duas árvores de decisões. Uma caso ele pertença ao grupo dos aldeões e outra caso esteja no grupo dos lobisomens. A última etapa é quando acontece a votação e os jogadores devem escolher um dos outros para eliminar, o jogador com mais votos será eliminado. Aqui é empregado o uso do NEAT, sua saída que deve informar ao NPC em qual jogador ele deve votar.

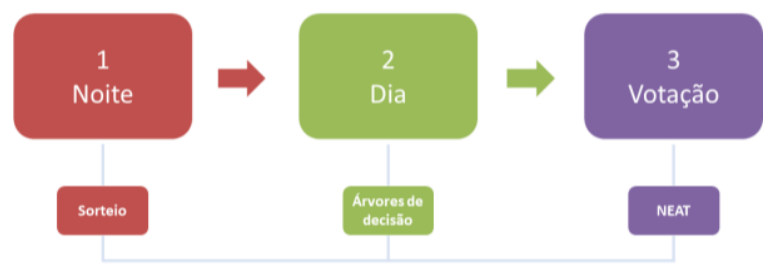

Figura 1: Etapas do jogo e as técnicas que serão aplicadas

A versão do jogo utilizada neste trabalho tem uma quantidade fixa de quatro jogadores. Além disso, a forma em que os jogadores se comunicam durante o jogo foi completamente repensada, de uma simples conversa aberta (na versão física do jogo), para uma abordagem com frases pré-estabelecidas. Esta modificação teve que ser feita, visto que realizar processamento de linguagem natural não está no escopo deste trabalho e a geração de uma comunicação semelhante à humana para o NPC também é algo a ser estudado em outros trabalhos.

Os jogadores do grupo dos aldeões podem apenas escolher dizer a verdade ou questionar outros jogadores. Já os lobisomens poderão montar frases contendo blefe, buscando confundir os outros jogadores.

Outra modificação realizada na etapa de conversa, foi a transformação dela em turnos, limitando a quantidade de interações possíveis, não mais por tempo, mas sim por quantidade de afirmações.

Como forma de mapear as informações ditas pelos jogadores ao decorrer do jogo e discretizá-lo foram criados dois tipos fichas de valores binários, uma delas com as possibilidades de afirmações para os jogadores, totalizando três fichas, uma para cada outro jogador (Quadro 1) e a outra possui apenas as informações que o NPC tem como certeza (Quadro 2). O Quadro 1 exibe de forma resumida a ficha com afirmações possíveis de serem feitas pelos outros jogadores.

\begin{tabular}{|c|c|}
\hline ID & Acontecimento \\
\hline 1 & Disse que é Aldeão \\
\hline 2 a 13 & $\begin{array}{c}\text { Disse ser Vidente e viu a carta do Jogador } \mathrm{N} \text { e que } \\
\text { era X personagem }\end{array}$ \\
\hline 14 a 18 & $\begin{array}{c}\text { Disse que é Vidente e olhou no meio e viu N cartas } \\
\text { do personagem X }\end{array}$ \\
\hline 19 a 26 & $\begin{array}{l}\text { Disse que era o Ladrão e trocou de carta com Jogador } \\
\qquad \mathrm{N} \text { e agora é o personagem X }\end{array}$ \\
\hline
\end{tabular}

Quadro 1: Ficha contendo as informações ditas pelos jogadores

O Quadro 2 exibe de forma resumida as informações que o NPC obteve como certeza durante a partida, como por exemplo: saber sua própria carta ou ver a carta de outro jogador.

\begin{tabular}{cc}
\hline ID & Informação \\
\hline 1 a 4 & Sou X personagem \\
5 a 16 & Jogador N é X personagem \\
\hline
\end{tabular}

\section{Quadro 2: Ficha com as informações que o NPC tem certeza}

O propósito da rede neural é dizer em qual dos outros jogadores o NPC deve votar ao final de cada partida. Para isso, assumindo que ele sempre será o jogador 1 , tem como entradas as informações obtidas e registradas em suas fichas. Ao todo a rede conta com 94 entradas e 4 saídas, sendo 78 referentes à uma ficha de informações ditas para cada um dos 3 jogadores, e 16 relativas à ficha das certezas do NPC, exibidas na Figura 2.

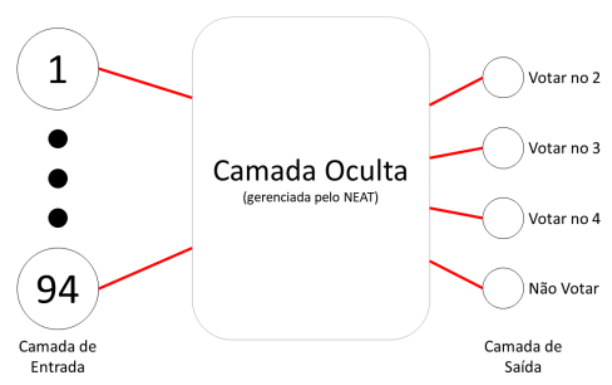

Figura 2: Visão do modelo da rede neural

Já o algoritmo genético do NEAT é responsável por gerenciar a topologia da rede neural do NPC, assim como suas conexões e pesos. Suas configurações são voltadas à criação de uma população com 100 indivíduos por geração, cada um contendo um genoma que descreve a topologia da rede neural do NPC.

O método a ser utilizado na seleção é o elitismo com o método de roleta, assim permitindo que os parte dos melhores indivíduos sejam mantidos e levados para as gerações futuras.

A aptidão de cada indivíduo é baseada no resultado de cada partida, verificando se o NPC está ou não no time vencedor. Além disso, o NPC também recebe bonificações de pontos por ações 


\section{Computer on the Beach}

que devem ser incentivadas e penalidades em comportamentos que devem ser reprimidos.

Como forma de avaliar a eficiência da técnica serão aplicados métodos baseados em trabalhos similares na área de teoria dos jogos. Por meio disso, descrevendo estratégias diferentes para compará-las com o que faz uso da técnica proposta, assim, obtendo-se, por exemplo, um NPC que vota de forma aleatória, outro que repete seu último voto, entre outras variantes. Dessa forma adquirindo outras métricas para comparar e observar se a técnica usada demonstra melhores escolhas analisando sua quantidade de vitórias.

\section{CONSIDERAÇÕES FINAIS}

A modelagem abordada se mostrou uma boa alternativa para descrever o jogo de tabuleiro em questão de forma discretizada, entretanto, para isso sendo necessário também ter um sistema de sorteio e de árvores de decisão. Assim, dispondo apenas de uma rede neural com NEAT, caso contrário, sem esses sistemas auxiliares seriam necessárias outras redes para gerenciá-los.

Através dos próximos estudos neste projeto será possível avaliar se esse tipo de abordagem é benéfico em problemas de natureza semelhante, entretanto com outras finalidades. Além disso, observar como a tecnologia lida com a falta de informações e o blefe.

\section{REFERÊNCIAS}

[1] Sweetser, P.; Wyeth, P. GameFlow: a model for evaluating player enjoyment in games. Computers in Entertainment (CIE), 2005.

[2] Novak, T. P.; Hoffman, D. L.; Duhachek, A. The influence of goal-directed and experiential activities on online flow experiences. Journal of consumer psychology, 2003.

[3] Anderson, T.; Stanley, K. O.; Miikkulainen, R. Neuro-Evolution Through Augmenting Topologies Applied To Evolving Neural Networks To Play Othello. University of Texas at Austin. Austin, p. 18. 2002.

[4] Tsoy, Y.; Spitsyn, V. Using genetic algorithm with adaptive mutation mechanism for neural networks design and training. Proceedings. The 9th Russian-Korean International Symposium on Science and Technology, 2005. KORUS 2005., 2005.

[5] Cutumisu, M. et al. Agent Learning using Action-Dependent Learning Rates in Computer Role-Playing Games. AIIDE, Edmonton, 2008. 8.

[6] Journey. 2012. [Video Game]. Thatgamecompany. Sony Interactive Entertainment.

[7] Henrique, Alisson Steffens, et al. Genetic Algorithm in Survival Shooter Games NPCs. Anais do Computer on the Beach 11, 1 (2020): 413-418.

[8] Henrique, Alisson Steffens, Vinicius Almeida dos Santos, and Rodrigo Lyra. NEAT Snake: a both evolutionary and neural network adaptation approach. Anais do Computer on the Beach 11, 1 (2020): 052-053.

[9] Baker, B. et al. Emergent tool use from multi-agent autocurricula. arXiv preprint arXiv: 1909.07528, 2019. 28.

[10] Alspach, T.; Okui, A. One Night Ultimate Werewolf - Bezier Games. Bezier Games, 2014. https://beziergames.com/collections/all-uw-titles/products/onenight-ultimate-werewolf

[11] Stanley, K. O.; Miikkulainen, R. Evolving neural networks through augmenting topologies. Evolutionary computation, 2002. 29. 